\section{P2-S8.03 DID YOU HEAR ABOUT THE 2010 STD TREATMENT GUIDELINES? RE-STRATEGIZING HOW WE E-COMMUNICATE ABOUT STD GUIDANCE}

\author{
doi:10.1136/sextrans-2011-050108.377
}

${ }^{1} \mathrm{M}$ A Habel, ${ }^{1} \mathrm{~L}$ Richman, ${ }^{1} \mathrm{~S}$ Haecker, ${ }^{1} \mathrm{R}$ Verma, ${ }^{2} \mathrm{~A}$ Meneghetti, ${ }^{1} \mathrm{R}$ Kachur, ${ }^{1} \mathrm{~B}$ Collins, ${ }^{1} \mathrm{R}$ Barnes, ${ }^{1} \mathrm{~N}$ Thompson, ${ }^{1} \mathrm{~K}$ Workowski. ${ }^{1} \mathrm{CDC}$, Atlanta, USA; ${ }^{2}$ Epocrates, San Mateo, USA

Background The 2010 STD Treatment Guidelines advise physicians and other health-care providers on the most effective diagnostic evaluation, treatment regimens, prevention and vaccination strategies for STDs. CDC revises the Guidelines approximately every 4 years, using a scientific, evidence-based process. Previous communication efforts around the Guidelines have lacked structured promotion and evaluation strategies. 2010 communication efforts strove to improve dissemination of this important resource in the public and private sector using traditional and novel communication technologies.

Methods The Guidelines were released online in the MMWR on 16 December 2010. A communication plan was devised involving an email distribution campaign, development of interactive elements such as webinars, podcasts, social media (Twitter), and mobile promotional efforts through a partnership with Epocrates. Clickthrough rates and web metrics were tracked using SiteCatalyst and tracking codes.

Results 45 days post-launch, the 2010 Treatment Guidelines web page was viewed 107174 times and downloaded 47,715 times making it the second most popular download on CDC's website. An email campaign targeting more than 54,000 individuals resulted in click-through rates well above worldwide government industry standard (3.3\%); ranging from $10 \%$ to $878 \%$ suggesting that emails were forwarded or the site was bookmarked. A January 13 live webinar resulted in 3200 registrations, 827 CMEs, and 742 evaluations. A podcast featured on Medscape was viewed 12296 times within 30 days; traffic was 3 times that of a June Chlamydia podcast. Preliminary Twitter data show that tweets were clicked on or retweeted at least 50 times during a 4-day period. A Dec 21 Epocrates DocAlert was delivered to 80795 devices in the first 10 days, 272857 devices by week 6 , and targeted to primary care, OB/Gyn, ID, ER, urologists, etc.; $22 \%$ of responders requested detailed information and links via email or via iPhone/Android on device.

Conclusions Data suggest (see Abstract P2-S8.03 Figure 1) that promotion efforts were highly successful as page view spikes coincided with email and mobile campaign pushes. Campaign tracking codes and web metrics are a simple way to evaluate health communication efforts and can offer insight on how well target audiences are being reached. Likewise, public health communicators should consider mutually beneficial partnerships with organizations that can reach providers in the private sector.

\section{P2-S8.04 GYT (GET YOURSELF TESTED) CAMPAIGN: GETTING YOUNG PEOPLE TALKING AND TESTED AND SPARKING A SOCIAL MOVEMENT}

doi:10.1136/sextrans-2011-050108.378

${ }^{1} \mathrm{~A}$ Friedman, ${ }^{2} \mathrm{M}$ Habel, ${ }^{2} \mathrm{R}$ Kachur, ${ }^{2} \mathrm{M}$ McFarlane, ${ }^{3} \mathrm{~L}$ Williamson, ${ }^{4} \mathrm{M}$ Mishel, ${ }^{5} \mathrm{~S}$ Levine, ${ }^{5} \mathrm{~A}$ Binns, ${ }^{2} \mathrm{C}$ Kapsimalis, ${ }^{6} \mathrm{~A}$ Patel. ${ }^{1}$ Centers for Disease Control $\mathrm{g}$ Prevention, Atlanta, USA; ${ }^{2}$ CDC, Atlanta, USA; ${ }^{3}$ MTV Networks, New York, USA; ${ }^{4}$ Henry J. Kaiser Family Foundation, USA; ${ }^{5}$ Kaiser Family Foundation, USA; ${ }^{6}$ Planned Parenthood Federation of America, USA

Background About 19 million new STDs occur each year in the USA, almost half of which are among youth. Lack of information, misconceptions and stigma prevent many from getting tested. To normalise conversations around sexual health and destigmatize testing, the GYT Campaign was launched in April 2009, with the goal of promoting STD testing among youth ages $15-25$ years.

Methods GYT was developed as part of It's Your (Sex) Life, a public information partnership of MTV and the Kaiser Family Foundation, together with the Centers for Disease Control and Prevention and Planned Parenthood Federation of America (PPFA). The campaign uses on-air, online, on-the-ground, and mobile components to increase STD testing and spark an empowering youth movement. It has expanded each year, reaching over 4,000 health centers nationwide, including school- and college-based health centers. Efforts to evaluate the campaign's reach and impact include media/materials tracking, national surveys, patient intake surveys at partnering clinics and schools, and the monitoring of STD test/positivity rates. Results At campaign launch, GYT was among the most-searched terms on Google, the most-tweeted terms on Twitter, and the most discussed videos on YouTube. As of January 2010, GYT had produced $>60$ public service ads and original programs, airing 3200 times on MTV stations (18 h of airtime), and had 1.5 million visitors to www.itsyoursexlife.com. A national survey suggests that campaign awareness among teens $(13-19$ years; $n=766)$ reached $18 \%$ in 2010 , with $10-20 \%$ reporting that they talked to a friend (21\%), family member $(18 \%)$, partner $(11 \%)$ or provider $(17 \%)$ about STDs/testing; and 10\% reporting having visited a doctor as a result of the campaign. Available data from participating PPFA clinics revealed a $71 \%$ increase in patients presenting for STI testing from April 2008 (pre-campaign) to April 2010, with a 25\% increase from April 2009-2010. Chlamydia positivity was 6\% among women and $9 \%$ among men during campaign promotion periods, indicating that GYT did not simply motivate the worried well.

Conclusions Research suggests that GYT is effectively reaching youth and impacting sexual-health discussions and STD-testing behaviours. The public-private partnership may serve as a model for other sexual health promotion programs. Creative ways for mobilising youth and lessons learnt about campaign branding, celebrity recruitment, and evaluation will be shared.

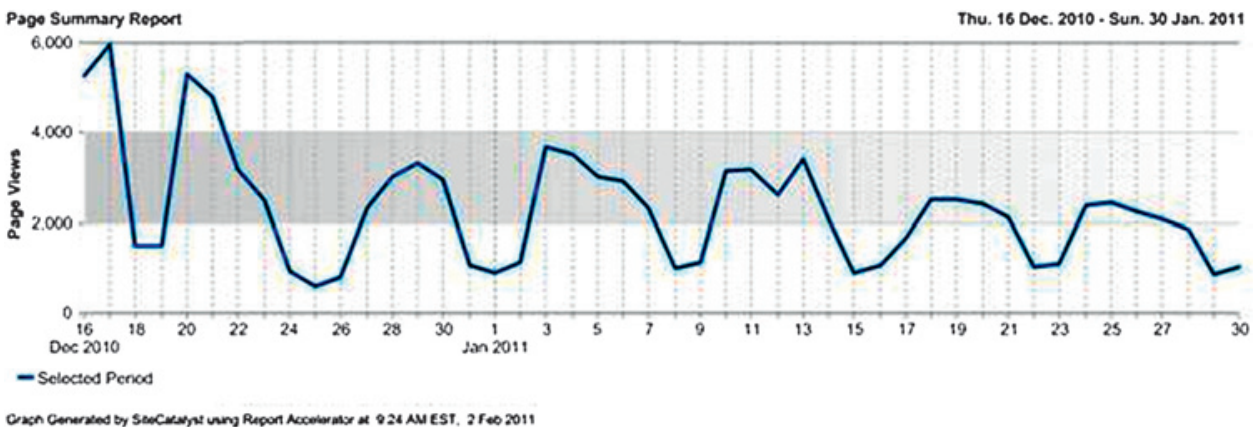

Abstract P2-S8.03 Figure 1 Number of page views to the STD Treatment Guidelines Homepage from 16 December 201030 January 2011. 